Otra historia para otra psiquiatría.

Rafael Huertas

Barcelona: Xoroi Edicions, 2017, 326 págs.

\title{
Combates por outra história da psiquiatria
}

\section{Struggles for a different history of psychiatry}

Rafael Huertas García Alejo é um dos principais historiadores da psiquiatria em âmbito mundial. Com produção vasta, é reconhecido pela relevância epistemológica e política dos seus trabalhos. Formado em medicina, fez-se historiador. Atualmente é chefe do Departamento de História da Ciência do Instituto de História do Centro de Ciências Humanas e Sociais (Madri). Para o conjunto de estudiosos da história da psiquiatria, Huertas é, ao menos nos últimos 15 anos, referência obrigatória. Suas orientadoras análises teórico-metodológicas têm sido nortes fundamentais. Nesse ponto, destaca-se a defesa das potencialidades heurísticas do uso das "polifônicas" fontes clínicas no desenvolvimento de uma "história vista de baixo" da psiquiatria, tendo no horizonte a construção do campo de estudos da "história cultural da subjetividade" (p. 267). Este rumo historiográfico é seguido no último capítulo de Otra historia (cap. 8).

${ }^{* 1}$ Fundação Oswaldo Cruz (Rio de Janeiro, RJ, Brasil). 
No livro, Huertas reescreve parte de sua produção das últimas duas décadas, revendo muitos temas. Para ele, a história da psiquiatria e da loucura deve ter lugar como "ferramenta epistemológica que nos permita entender, entre outras coisas, o caráter histórico-cultural dos transtornos mentais" (p. 23). A centralidade das questões do presente nesta obra é clara, e segue a esteira das propositivas da "história-problema" da Escola dos Annales. Pensando passado e presente dialeticamente, Huertas vem traçando "combates" por uma história da psiquiatria que não sirva para tecer loas ao organicismo, mas para repensar a clínica.

Os capítulos do livro passam por muitos objetivos: caracterizar o alienismo de início do oitocentos como uma "filosofia da loucura" com vistas a uma "higiene da alma", vendo assim como a exploração da subjetividade foi constitutiva da semiologia psiquiátrica e, de início, não em relação de oposição com as concepções anatomoclínicas (cap. 1 e 3); compreender os debates em torno da "psicose única", sua formulação em Esquirol e depois dele (cap. 2); a evolução, antes de Freud, do conceito de "obsessão" (cap. 5) etc.

Huertas faz o que na história da historiografia chamamos de "contextualismo linguístico". A ideia é a de que o acesso possível do historiador ao "presente das necessidades práticas" dos atores de tempos passados se dá pelas linguagens compartilhadas por esses atores, pelos textos que produziam e faziam circular, pelos projetos colocados em prática e pelas comunidades de debate em que estavam inscritos (Pocock, 2003, p. 38). Huertas discute expectativas presentes em teorizações, historicizando conceitos a partir de exame intertextual. Nesse sentido, tomando as bases da história conceitual da psiquiatria, acompanha as continuidades e inflexões no devir histórico das racionalidades clínicas.

Três capítulos merecem especial atenção. Em "El concepto de perversão sexual" (cap. 4) lança luz sobre momentos da formação de ideias psiquiátricas e médico-legais sobre as "perversões sexuais", destrinchando a tradição alienista francesa nessa seara. A ideia de "perversão" inaugura novo terreno epistemológico: o desvio da "norma moral" passa a desvio da "lei natural". Com a emergência do paradigma degeneracionista, consolida-se a aproximação da loucura com a imoralidade. O historiador mostra como, no degeneracionismo, soma-se à "sintomatologia clínica" das perversões uma "estigmatologia física". Com Magnan e Charcot (2002), assiste-se à formulação de um modelo neurofisiológico e anatômico das perversões; passa a importar mais compreender a estrutura patológica, os "signos físicos do desequilíbrio mental" do pervertido sexual, e menos seus atos em si. Nesse contexto, Freud (1901-1905/2016) introduziu um importante lance teórico ao não interpretar as perversões como inteiramente patológicas. O diálogo com Foucault (2005) é evidente, mas sempre aprofundado por injunções analíticas advindas de outras leituras. Aqui, Huertas assume 


\section{RESENHAS BIBLIOGRÁFICAS}

os riscos que uma perspectiva analítica de longa duração traz, às vezes passando por cima das polifonias existentes nas comunidades de debate.

No capítulo 6, intitulado "Locos, criminales y psiquiatras", defende relevante ideia de um "modelo médico da criminalidade". Retomando o pressuposto segundo o qual a entrada da psiquiatria na seara da justiça penal foi fundamental na legitimação da psiquiatria, Huertas aborda a trajetória do conceito de monomania no interior do alienismo francês do século XIX, bem como suas absorções e resistência no mundo jurídico. Demonstra como o aparato conceitual degeneracionista e a outra chave interpretativa estigmatológica que aproximou crime e loucura, a antropologia criminal, sociais e juridicamente mais convincentes, derrocaram a noção de monomania. Os primeiros anos do século XX assistem ao amalgamento das concepções de etiologia criminal. O historiador madrilenho, combatendo por "outra psiquiatria", defende o fim do conceito de periculosidade como instrumento de reformulação do lugar do portador de sofrimento psíquico que infringiu a lei penal. O capítulo é muito válido para aqueles que, como o autor desta resenha, vem tentando pensar como os idiomas médico-psicológicos são discutidos por juristas e como os segmentos profissionais contestam mutuamente jurisdições e legitimidades, o que produz modificações nos dois campos.

No capítulo "El poder psiquiatrico" (cap. 7) faz uma releitura do curso de Foucault no College de France de mesmo título. O objetivo é desnudar as formas de violência que podem decorrer do poder psiquiátrico e das suas formas de produção da verdade. Para Huertas, assim como para Foucault, a "psiquiatria é uma disciplina de poder antes que uma ciência médica" (p. 237). No entanto, o historiador espanhol salienta algumas limitações da arqueogenealogia desenvolvida no livro de Foucault (2005): seu pouco potencial para reconstruir intenções e sensibilidades, enfim, a experiência dos sujeitos, psiquiatras e pacientes; e o fato de escapar do conceito arqueogenealógico de poder muitos aspectos, sobretudo aqueles que dizem respeito aos processos de construção de legitimidade profissional. Ao final, mostra como a leitura de "O poder psiquiátrico" pode ser arma contra a força estigmatizante dos diagnósticos psiquiátricos.

Algumas generalizações presentes na narrativa - "ciência positivista", "psiquiatria biológica", "medicalização" — geram certa inquietude, bem como o acento nas conexões estruturais entre a psiquiatria e moral burguesa e controle social. No capítulo sobre as "perversões sexuais", por exemplo, a psiquiatria, "fiel aliada do poder e da norma" (p. 138), assombra as subjetividades homossexuais. A linha de continuidade entre vício, pecado e doença, reiterada por Huertas para a história das perversões, tem sido matizada pela historiografia interessada na construção cultural do "homossexual". Também é passível de relativização a assertiva de que o conceito de responsabilidade penal foi substituído pelo de 
periculosidade. Estes são elementos pontuais que não comprometem os cuidados analíticos e a atualização historiográfica desta obra agora essencial.

\section{Referências}

Charcot, J. M; Magnan, V. (2002). Perversiones. Jaén: Ediciones del lunar.

Foucault, M. (2005). El poder psiquiátrico. Madrid: Akal.

Freud, S. (2016). Obras completas, volume 6: três ensaios sobre a teoria da sexualidade, analise fragmentária de uma histeria ("O caso Dora") e outros textos. São Paulo, SP: Companhia das Letras. (Trabalho original publicado em 1901-1905).

Pocock, J. (2003). Linguagens do ideário político. São Paulo, SP: Edusp.

Citação/Citation: Dias, A. A. T. (2018, junho). Combates por outra história da psiquiatria. Resenha do livro Otra historia para otra psiquiatría. Revista Latinoamericana de Psicopatologia Fundamental, 21(2), 399-402. http://dx.doi.org/10.1590/1415-4714.2018v21n2p399.12

Editores do artigo/Editors: Profa. Dra. Sonia Leite e Profa. Dra.Marta Regina de Leão D'Agord

Recebido/Received: 7.2.2018 / 2.7.2018 Aceito/Accepted: 25.2.2018 / 2.25.2018

Copyright: (C) 2009 Associação Universitária de Pesquisa em Psicopatologia Fundamental/ University Association for Research in Fundamental Psychopathology. Este é um artigo de livre acesso, que permite uso irrestrito, distribuição e reprodução em qualquer meio, desde que o autor e a fonte sejam citados / This is an open-access article, which permits unrestricted use, distribution, and reproduction in any medium, provided the original authors and sources are credited.

\section{Allister Andrew Teixeira Dias}

Bacharel e licenciado em História pela Universidade Federal Fluminense (Rio de Janeiro, RJ, Br); Mestre e Doutor em História das Ciências pela Fundação Oswaldo Cruz (Rio de Janeiro, RJ, Br); Membro da Red Iberoamericana de História de la Psiquiatria. Atualmente realiza pós-doutorado no Departamento de Pesquisa da Casa de Oswaldo Cruz - Fundação Oswaldo Cruz (Rio de Janeiro, RJ, Br) e é Professor Substituto no Instituto de Estudos em Saúde Coletiva da Universidade Federal do Rio de Janeiro - UFRJ (Rio de Janeiro, RJ, Br). Rua Barão de Sertório, 62, Casa - Rio Comprido 20261-050 Rio de Janeiro, RJ, Brasil allisterdias@hotmail.com

\section{(cc) BY-NC}

This is an open-access article, which permits unrestricted use, distribution, and reproduction in any medium for non-commercial purposes provided the original authors and sources are credited. 